\title{
Short communication: Use of genomic and metabolic information as well as milk performance records for prediction of subclinical ketosis risk via artificial neural networks
}

\author{
A. Ehret, ${ }^{* 1}$ D. Hochstuhl, $\dagger$ N. Krattenmacher, ${ }^{*}$ J. Tetens, ${ }^{*}$ M. S. Klein,$\ddagger^{2}$ W. Gronwald, $\ddagger$ and G. Thaller* \\ *Institute of Animal Breeding and Husbandry, and \\ †Institute for Theoretical Physics and Astrophysics, Christian-Albrechts-University, 24098 Kiel, Germany \\ †Institute of Functional Genomics, University of Regensburg, 93053 Regensburg, Germany
}

\section{ABSTRACT}

Subclinical ketosis is one of the most prevalent metabolic disorders in high-producing dairy cows during early lactation. This renders its early detection and prevention important for both economical and animalwelfare reasons. Construction of reliable predictive models is challenging, because traits like ketosis are commonly affected by multiple factors. In this context, machine learning methods offer great advantages because of their universal learning ability and flexibility in integrating various sorts of data. Here, an artificialneural-network approach was applied to investigate the utility of metabolic, genetic, and milk performance data for the prediction of milk levels of $\beta$-hydroxybutyrate within and across consecutive weeks postpartum. Data were collected from 218 dairy cows during their first 5 wk in milk. All animals were genotyped with a 50,000 SNP panel, and weekly information on the concentrations of the milk metabolites glycerophosphocholine and phosphocholine as well as milk composition data (milk yield, fat and protein percentage) was available. The concentration of $\beta$-hydroxybutyric acid in milk was used as target variable in all prediction models. Average correlations between observed and predicted target values up to 0.643 could be obtained, if milk metabolite and routine milk recording data were combined for prediction at the same day within weeks. Predictive performance of metabolic as well as milk performancebased models was higher than that of models based on genetic information.

Key words: artificial neural network, prediction, ketosis, milk metabolite

Received July 11, 2014.

Accepted September 15, 2014.

${ }^{1}$ Corresponding author: aehret@tierzucht.uni-kiel.de

${ }^{2}$ Current affiliation: Faculty of Kinesiology, University of Calgary, Alberta, Canada.

\section{Short Communication}

In dairy cattle, breeding for an increased milk yield has led to a pronounced energy deficit postpartum (Veerkamp and Koenen, 1999). Cows experiencing a strongly negative energy balance in early lactation are more prone to metabolic disorders (Collard et al., 2000). Ketosis or acetonemia is one of the most prevalent metabolic disorders in high-producing dairy cows, showing the highest incidence within the first weeks of lactation (Duffield et al., 2009; Asl et al., 2011). Although clinical cases are comparatively rare, prevalences of up to $28.3 \%$ have been reported for subclinical ketosis in European countries (Suthar et al., 2013). Subclinical stages of ketosis are associated with decreased milk production and an increased risk of displaced abomasum, lameness, and metritis (Dohoo and Martin, 1984). Detection of the preclinical disease stages would allow for a timely treatment of affected animals, which is beneficial from an economic and an animal-welfare point of view (Asl et al., 2011). Subclinical ketosis (SCK) is characterized by an increased production of ketone bodies, such as BHBA, acetone, and acetoacetate in the absence of clinical signs of ketosis (Andersson, 1988). Ketone-body concentrations can be readily measured in blood or milk (Enjalbert et al., 2001), and BHBA levels in blood are well-established indicators of early-stage SCK (Dohoo and Martin, 1984; Duffield et al., 1997; Suthar et al., 2013). A serum BHBA concentration of $\geq 1,200$ to $1,400 \mu \mathrm{mol} / \mathrm{L}$ is typically defined as SCK (Geishauser et al., 2000; LeBlanc, 2010). However, even cows with serum BHBA concentrations exceeding 1,000 $\mu \mathrm{mol} / \mathrm{L}$ in the first week of lactation are already almost 14 times more likely to develop displaced abomasum (Seifi et al., 2011). Concentrations of BHBA have been reported to be approximately 10 times smaller in milk as compared with plasma (Klein et al., 2013), and equivalently smaller threshold concentrations have to be applied in ketosis detection. The correlation between BHBA concentrations in milk and blood has been reported to be 0.8 by Klein et al. (2013) but found to be 
as low as 0.52 in a study by van der Drift et al. (2012a). Although BHBA can be more readily measured in milk under practical conditions, disease status can more precisely be determined from blood (van Knegsel et al., 2010).

Exceeding a certain BHBA threshold indicates an already existing ketotic state, but to reach the goal of ultimately preventing SCK, an early forecast of individual ketosis risk is required. However, prediction of functional traits, which are commonly affected by multiple factors, is extremely challenging. Typically, those traits are characterized by a low heritability, and phenotypic measurements are often costly and not part of routine recording. Thus, it is reasonable to exploit new sources of information (e.g., performance records, metabolic and genomic information) for the detection of preketotic metabolic conditions. For such purposes, machine learning methods such as artificial neural networks (ANN) are promising tools. They are able to learn specific data patterns and especially ANN are considered universal approximators of any type of arithmetic function (Hornik et al., 1989). Artificial neural networks are able to cover cryptic interactions between various predictors and response variables without a need to explicitly specify a fixed model. For the prediction of ketosis risk this approach allows for the simultaneous incorporation of different types of information to enhance prediction accuracy and performance.

A recent study on potential predictor variables for ketosis showed that dairy cows with ratios of milk glycerophosphocholine (GPC) to milk phosphocholine (PC) equal or greater than 2.5 are significantly less prone to ketosis within and over subsequent lactations (Klein et al., 2012). Raised GPC/PC ratios and GPC concentrations in milk are believed to reflect the ability of an animal to mobilize fatty acids from the breakdown of blood phosphatidylcholines rather than from body fat as a source for milk lipid synthesis (Klein et al., 2012). Additionally, genome-wide association studies revealed marker genotypes associated with ketosis-linked factors (Buitenhuis et al., 2013; Tetens et al., 2013; Gaddis et al., 2014), underscoring the potential contribution of genetic factors to disease development. Furthermore, changes in milk composition are an indirect indicator of the health status of a cow (e.g., Hamann and Krömker, 1997). The close relationship between metabolic disorders and energy balance (EB) allows for the use of EB traits (such as fat-to-protein ratio) in the prediction of disease risk (Buttchereit et al., 2010). Performance records for milk yield and milk composition such as fat and protein percentage, protein-to-fat ratio, as well as DMI are promising indicators for the susceptibility to metabolic disorders (Duffield et al., 1997).
The main objective of this study was to systematically assess the applicability of different sources of information in predicting subclinical ketosis in early lactation. Prediction was accomplished via ANN for the same day within one week and for consecutive weeks (forecast). The concentration of BHBA in milk is a direct measure of the ketotic state of a cow and was used as the target variable. Several combinations of metabolic and genetic information as well as performance records of cows from the first weeks of lactation were used alone and in various combinations as predictor variables, and their influence on prediction accuracy was investigated.

Genomic and metabolic data as well as information on milk yield and milk composition of 218 high-yielding dairy cows in early lactation were available. Data were collected between October 2008 and June 2010 on the dairy research farm Karkendamm, which is affiliated with the Institute of Animal Breeding and Husbandry of Kiel University, Germany. The cows were milked twice daily and fed a TMR diet ad libitum. Composition of TMR varied slightly over the observation period. However, CP, bypass protein, and the $\mathrm{NE}_{\mathrm{L}}$ of $\mathrm{TMR}$ were kept relatively constant. The $\mathrm{NE}_{\mathrm{L}}$ of $\mathrm{TMR}$ ranged between 6.9 and $7.2 \mathrm{MJ} / \mathrm{kg}$ of DM. According to von Leesen et al. (2014), who studied the energy status of primiparous Karkendamm cows (data recording period: March 2006 to December 2012), (i) the cows on average exhibited an energy deficit during the first $55 \mathrm{~d}$ in milk and (ii) none of the cows turned to a positive EB before d 20 in milk.

Milk samples were collected weekly during the first 5 wk in milk. Eighteen animals had full records for 5 consecutive weeks and 41 animals had complete records for 4 consecutive weeks, but the vast majority of cows $(\mathrm{n}=159)$ had consecutive records for only 3 or less weeks. Although precluding the analysis of time series for predicting the SCK risk, 611 weekly records of 218 cows were available for the prediction within and across consecutive weeks as shown in Table 1. The milk levels of GPC and PC as well as their ratio were used as predictor variables, whereas the concentration of BHBA in milk (see Figure 1) served as the target variable. The 3 variables had been measured by nuclear magnetic resonance spectroscopy as described previously (Klein et al., 2012). Additionally, for all cows weekly milk performance records of milk yield and protein and fat percentage were available.

All animals were genotyped using the Illumina BovineSNP50 BeadChip (Illumina Inc., San Diego, CA) comprising a total number of 54,001 SNP. The SNP with a minor allele frequency $<0.05$ and missing genotype frequency $>0.05$ were discarded from the analyses, resulting in final set of 41,423 markers. Sporadically 
Table 1. Structure of data sets used for the prediction of milk BHBA within and across the first 5 wk in milk

\begin{tabular}{lcc}
\hline $\begin{array}{l}\text { Lactation week in } \\
\text { which predictors } \\
\text { were recorded }\end{array}$ & $\begin{array}{c}\text { Lactation week } \\
\text { for which BHBA } \\
\text { was predicted }\end{array}$ & $\begin{array}{c}\text { No. of animals } \\
\text { with complete } \\
\text { records }\end{array}$ \\
\hline Within weeks & 1 & \\
1 & 2 & 60 \\
2 & 3 & 121 \\
3 & 4 & 149 \\
4 & 5 & 142 \\
5 & 2 & 119 \\
Across weeks (forecast) & 3 & 34 \\
1 & 4 & 85 \\
2 & 5 & 101 \\
3 & 5 & 83 \\
4
\end{tabular}

${ }^{1}$ Milk concentrations of glycerophosphocholine and phosphocholine, and milk performance records.

missing genotypes were imputed using the populationbased imputing algorithms $\mathrm{MaCH}$ (Li et al., 2010) and its extension Minimac (Howie et al., 2011).

Aiming at a reduction of model complexity and computational cost, genomic information was incorporated in the prediction using the principal component scores, referred to as UD matrix, of the original genotype matrix $\mathbf{X}$. The UD matrix is of dimension $n \times n$, with $n$ being the number of animals and is obtained from the singular value decomposition of the original genotype matrix X (Mandel, 1982):

$$
\mathbf{X}=\mathbf{U D V}^{\prime}
$$

Here, $\mathbf{U}$ is an orthogonal matrix and the columns are the eigenvectors of $\mathbf{X} \mathbf{X}^{\prime} ; \mathbf{D}$ is a matrix containing the square roots of the nonzero eigenvalues of $\mathbf{X}^{\prime} \mathbf{X}$, and the columns of $\mathbf{V}$ are the eigenvectors of $\mathbf{X}^{\prime} \mathbf{X}$ (Tusell et al., 2013). The UD decomposition reexpresses the data taking its variance into account.

Additionally, feature scaling was performed for all metabolites, metabolite ratios, and milk performance records as well as for the UD matrix to incorporate different variables measured on different scales into the model. Basically, feature scaling is a normalization process where variables are linearly transformed. To

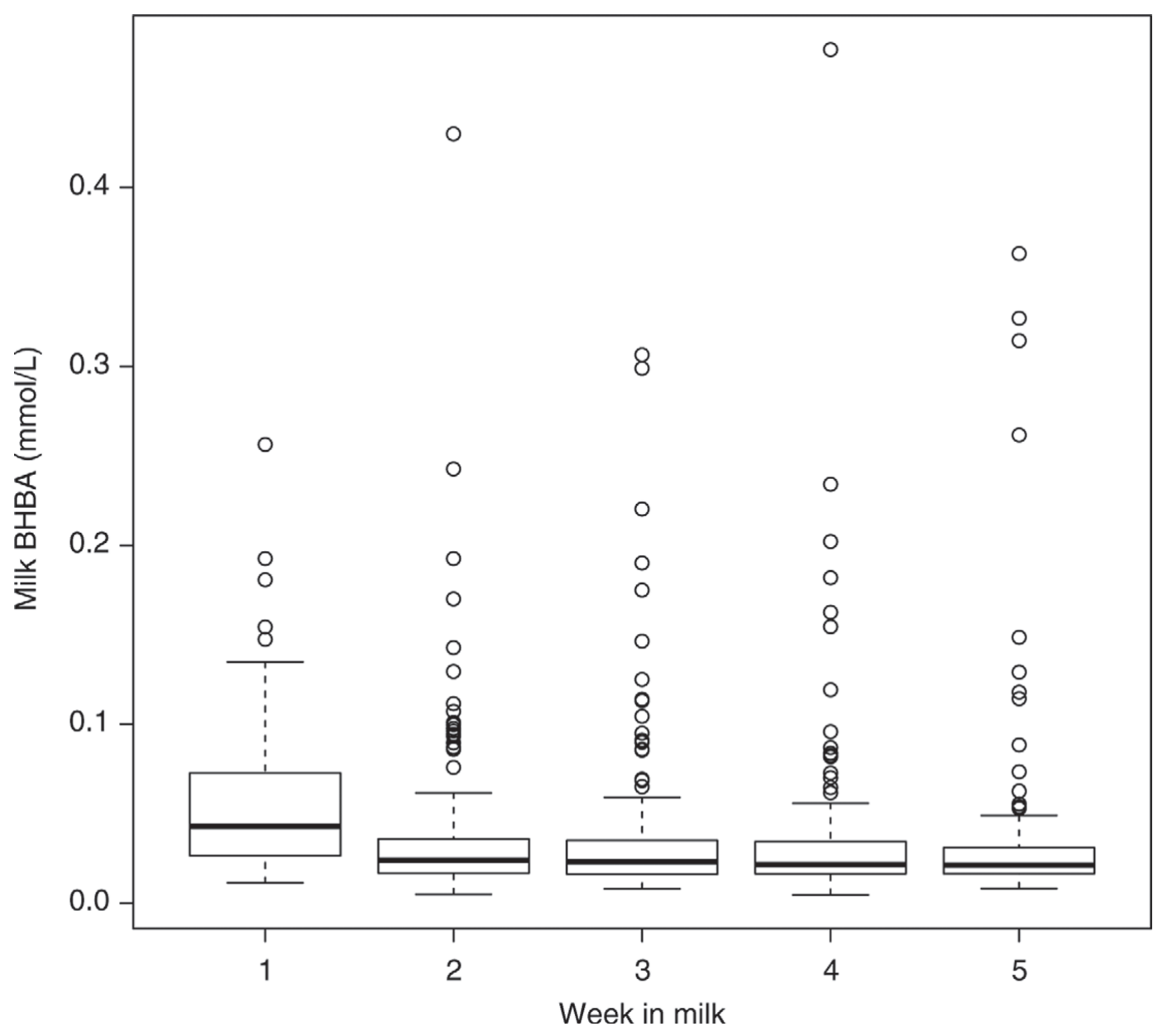

Figure 1. Boxplots of BHBA concentrations in milk samples across the first 5 wk in milk. 
achieve the scaling of all elements to a range between -1 and 1 , the normalization function of Pérez-Rodriguez et al. (2013) was used.

For prediction, a multilayer feed-forward ANN was used, which is part of a wide range of machine learning methods for data-mining processes. Artificial neural networks are very flexible prediction machines allowing for the incorporation of several types of data. According to the learning rule, an ANN can be trained for predicting unknown outcomes of the same task as training samples. For further information, in particular to applications concerning animal and plant science, we refer to Gianola et al. (2011).

We implemented a single hidden layer feed-forward network with 5 neurons in the hidden layer and a learning rate equal to 0.02 . For further information regarding fitting ANN we refer to Kriesel (2007). Furthermore, we employed the nonlinear hyperbolic tangent function to the hidden neurons, aiming at giving the network a greater flexibility for capturing the relation between different combinations of information sources and milk BHBA concentrations (in the following also referred to as SCK risk). In the output layer one neuron with a linear activation was used. For the training process a regularized back-propagation algorithm was used, which corresponds to a nonlinear least squares optimization. All models were run using a $\mathrm{C}++$ program written by the authors, whereas data preprocessing was done in $\mathrm{R}$ (version 2.14.1, R Development Core Team, 2010).

We evaluated the predictive performance of several models for SCK risk. In detail, we investigated different combinations of information to assess their effect on prediction ability of BHBA concentrations, within and across consecutive weeks. An overview of all chosen prediction models is presented in Table 2 .

Taking into account the small sample size, we applied a 5 -fold cross validation with 100 individual repetitions (Kohavi, 1995) to properly assess the predictive ability of the different models within and between consecutive weeks. Cross-validation for prediction models was performed by randomly dividing data sets into 5 subsets of predictor combinations and corresponding BHBA status of individual animals, having no missing values for the desired combination of information. One subset (testing set) was left out to evaluate the predictive ability of the model, whereas the other 4 subsets were used as a training set to configure the ANN. This scheme was rotated so that each subset served as testing set once. In each of the 5 rounds the BHBA concentrations of the testing set were set to missing, and Pearson correlation between observed and predicted response were calculated. One hundred different randomizations assigning the different combination of predictors and corresponding BHBA status to 5 different subsets were used, yielding 500 independent cross-validation runs per model. The predictive ability of each model was then calculated as Pearson correlation ( $\mathrm{r}$ ) between the observed and predicted BHBA concentration averaged over all 500 cross-validation runs. Furthermore, a multiple contrast test (Tukey's honestly significant difference test; HSD) was applied to cross-validation results, to indicate possible significant differences between single models (note that in the following, results from HSD test are not completely shown). The HSD was applied simultaneously to the set of all pairwise comparisons and identifies differences between 2 means that are greater than the expected standard error.

\section{Prediction of Subclinical Ketosis Risk Within Weeks}

Table 3 shows the average Pearson correlation coefficient between observed and predicted BHBA concentrations of 500 independent cross-validation runs for the different models (Mod1-9, upper part of Table 2). Generally, because of the small number of animals with full records for all available sources of information, variance in calculated correlations between observed and predicted phenotype in CV runs was high (Table 3). Furthermore, the very limited number of clinical ketosis cases with very high BHBA levels (Figure 1) might in particular contribute to the high variance. Depending on the distribution of the animals with outstandingly high BHBA levels between training and testing set,

Table 2. Schematic overview of selected combinations of information sources for the different prediction models

Prediction

model

(Mod) $\quad \mathrm{GPC} / \mathrm{PC}^{1} \quad \mathrm{GPC}+\mathrm{PC} \quad \mathrm{MPR}^{2} \quad \mathrm{UD}^{3}$

Within weeks

Mod1

$\operatorname{Mod} 2$

$\operatorname{Mod} 3$

Mod4

Mod5

Mod6

$\operatorname{Mod} 7$

$\operatorname{Mod} 8$

Mod9

Across weeks

Mod1

$\operatorname{Mod} 2$

$\operatorname{Mod} 3$

Mod4

Mod5

Mod6

$\operatorname{Mod} 7$

$\mathrm{X}$

$\mathrm{X}$

$\mathrm{X}$

${ }^{1} \mathrm{GPC} / \mathrm{PC}=$ ratio of glycerophosphocholine (GPC) to phosphocholine (PC).

${ }^{2} \mathrm{MPR}=$ milk performance records (milk yield, fat and protein percentage).

${ }^{3} \mathrm{UD}=$ principal component scores of genotypes. 
Table 3. Results of predictions at the same day within weeks ${ }^{1}$

\begin{tabular}{|c|c|c|c|c|c|c|}
\hline Prediction model $(\mathrm{Mod})^{2}$ & Wk 1 p.p. & Wk 2 p.p. & Wk 3 p.p. & Wk 4 p.p. & Wk 5 p.p. & Average $^{3}$ \\
\hline Mod1 (GPC/PC) & $\begin{array}{c}-0.027 \\
(0.073)\end{array}$ & $\begin{array}{c}0.005 \\
(0.037)\end{array}$ & $\begin{array}{c}0.278 \\
(0.015)\end{array}$ & $\begin{array}{c}0.140 \\
(0.017)\end{array}$ & $\begin{array}{c}0.193 \\
(0.027)\end{array}$ & 0.118 \\
\hline Mod2 (GPC + PC) & $\begin{array}{r}-0.127 \\
(0.066)\end{array}$ & $\begin{array}{c}0.085 \\
(0.040)\end{array}$ & $\begin{array}{l}0.545 \\
(0.065)\end{array}$ & $\begin{array}{c}0.322 \\
(0.129)\end{array}$ & $\begin{array}{l}0.255 \\
(0.050)\end{array}$ & 0.216 \\
\hline Mod3 (MPR) & $\begin{array}{c}0.489 \\
(0.064)\end{array}$ & $\begin{array}{c}0.393 \\
(0.027)\end{array}$ & $\begin{array}{l}0.335 \\
(0.023)\end{array}$ & $\begin{array}{c}0.542 \\
(0.040)\end{array}$ & $\begin{array}{c}0.463 \\
(0.037)\end{array}$ & 0.444 \\
\hline Mod4 (UD) & $\begin{array}{c}0.453 \\
(0.060)\end{array}$ & $\begin{array}{c}-0.011 \\
(0.041)\end{array}$ & $\begin{array}{c}0.095 \\
(0.024)\end{array}$ & $\begin{array}{l}0.198 \\
(0.031)\end{array}$ & $\begin{array}{l}0.043 \\
(0.035)\end{array}$ & 0.156 \\
\hline Mod6 $(\mathrm{GPC}+\mathrm{PC}+\mathrm{UD})$ & $\begin{array}{l}0.408 \\
(0.067)\end{array}$ & $\begin{array}{c}0.032 \\
(0.035)\end{array}$ & $\begin{array}{c}0.259 \\
(0.026)\end{array}$ & $\begin{array}{c}0.274 \\
(0.040)\end{array}$ & $\begin{array}{l}0.170 \\
(0.035)\end{array}$ & 0.229 \\
\hline Mod7 (MPR + UD) & $\begin{array}{l}0.528 \\
(0.059)\end{array}$ & $\begin{array}{c}0.135 \\
(0.033)\end{array}$ & $\begin{array}{l}0.278 \\
(0.020)\end{array}$ & $\begin{array}{l}0.484 \\
(0.020)\end{array}$ & $\begin{array}{c}0.349 \\
(0.033)\end{array}$ & 0.355 \\
\hline Mod8 $(\mathrm{MPR}+\mathrm{GPC}+\mathrm{PC})$ & $\begin{array}{c}0.439 \\
(0.047)\end{array}$ & $\begin{array}{c}0.212 \\
(0.045)\end{array}$ & $\begin{array}{c}0.519 \\
(0.048)\end{array}$ & $\begin{array}{c}0.643 \\
(0.068)\end{array}$ & $\begin{array}{c}0.371 \\
(0.067)\end{array}$ & 0.437 \\
\hline
\end{tabular}

${ }^{1}$ Shown are the average Pearson's correlation coefficients between observed and predicted BHBA concentrations in milk over all 500 CV runs (the variance of estimates is given in parentheses). p.p. = postpartum.

${ }^{2} \mathrm{GPC} / \mathrm{PC}=$ ratio of glycerophosphocholine $(\mathrm{GPC})$ to phosphocholine $(\mathrm{PC}), \mathrm{MPR}=$ milk performance records (milk yield, fat and protein percentage), $\mathrm{UD}=$ principal component scores of genotypes.

${ }^{3}$ Averaged over all $5 \mathrm{wk}$.

predictive performance can become poor for the upper concentration range (Kriesel, 2007). Using a data set with more clinical cases or restricting the data set to a certain BHBA range, which was precluded by the small sample size here, might well result in a much better performance.

The results indicate that prediction of SCK risk works sufficiently well in wk $1,3,4$, and 5 postpartum. On average and considering all implemented models, Pearson correlations of $0.348,0.306,0.369$, and 0.256 , respectively, could be obtained for respective weeks in milk. In comparison, predictive performance was, for unknown reasons, worse in wk 2 postpartum (correlation averaged over all models $r=0.110)$. Against the background of the small sample size, however, animals with particular patterns of predictor values might have biased predictions. Overall, the predictive performance of ANN within weeks varied strongly with the combination of predictors.

As shown in Table 3, the prediction performance was, irrespective of the inclusion of genetic information, significantly better when using the absolute abundances of GPC and PC rather than using their ratio (GPC/ $\mathrm{PC})$ as input to the network. The only exception is lactation wk 1, where the ratio combined with the UD matrix achieved an average predictive performance of $r$ $=0.439$, whereas the single metabolites combined with the genetic information resulted in a performance of $r=0.408$. However, evidence is limited, because the difference was not significant (HSD). These results lead to the assumption that the relationship between me- tabolites is not linear; thus, the ANN is able to capture the relationship better through separate information of single metabolites than through a linear combination. However, when metabolic information represented the only source of input information, predictions failed for the first $2 \mathrm{wk}$ postpartum. This effect might be due to the fast changes in metabolic constitutions of animals in the first weeks of lactation. In wk 1, the prediction performance increased significantly when genetic information was added to the metabolic models. Combinations of metabolic and genetic information as predictors achieved no significant improvement, rather than a decline, in predictive ability in all other weeks. These results indicate that genetic information of 50,000 SNP panels has low informative character as predictor of BHBA status. This might, however, also be due to statistical limitations, because the inclusion of genomic information in predictions increases the number of parameters to be estimated and, thus, increases model complexity.

Overall, the highest prediction performances and lowest variances of cross-validation runs were obtained with the use of both milk performance and metabolite data. This effect is independent of the data set (weeks postpartum) used for the analyses.

Predictive ability of the genetic covariates as the only information to the networks was best in the first week and decreased with increasing number of weeks postpartum, which might indicate a decrease of heritability during lactation. This is in line with Oikonomou et al. (2008), who reported heritability estimates for 
serum BHBA concentrations to drop from 0.40 in the first lactation week to 0.08 in wk 7 . To analyze the trajectory of heritability throughout lactation, random regression models can be used, which is hardly possible in the current study owing to the limited amount of data. Moreover, it is known from literature that the use of random regression for disease data often results in erratic estimates and computational difficulties, especially when disease frequencies are low (Carlén et al., 2009).

Our results show that the benefit of genetic information to increase predictive ability of the prediction model is low. The use of the genomic covariates led to a significant increase of predictive performance of models for wk 1 only, but for all other weeks, this was not true. Generally, adding genomic information to the prediction models led to a significantly higher predictive performance in $20 \%$ of the models. However, $60 \%$ of the models performed significantly worse than the reduced model without genomic information. The results therefore indicate that the exclusive use of genetic covariate information fails in the prediction of SCK risk. This is in concordance with the low heritability of ketosis and BHBA concentrations reported in literature [e.g., Gaddis et al., $2014\left(\mathrm{~h}^{2}=0.04-0.14\right.$ for clinical ketosis), Heringstad et al., $2005\left(\mathrm{~h}^{2}=0.13-0.15\right.$ for clinical ketosis), van der Drift et al., 2012b $\left(\mathrm{h}^{2}=0.16\right.$ and 0.17 for milk and serum BHBA, respectively)]. Furthermore, we suppose that a higher number of animals would have been needed to make SNP-based predictions valuable. And finally, static distribution of genotypes might have an effect because they are not able to capture the changes of BHBA concentrations of animals within weeks. Furthermore, using the UD matrix might have somewhat blurred genetic information, as single information got lost upon transforming genotype information into principal component scores. Nevertheless, transformation was needed to make regression with low sample size feasible.

The use of weekly milk performance records (milk yield, protein and fat percentage) as input information to the prediction model consistently led to high prediction performance of BHBA status of cows in early lactation and, thus, to a good mapping of SCK risk. This was irrespective of the week that was studied. As mentioned before, the high negative EB, which is determined by milk yield and can be described by milk composition in early lactation, is one of the most critical precursors for metabolic disorders (e.g., Hamann and Krömker, 1997). Indeed, the milk-related predictors showed an appropriate capability to predict the BHBA status of cows properly within weeks. Furthermore, a combination of milk performance records with metabolic information seems to give a stable and well-performing predictive system.

Additionally, it would have been interesting to include DMI as another variable with a substantial effect on the energy status of a cow in the predictive model, but because of technical issues, this information was not available to us. However, under field conditions milk performance records such as milk yield and protein and fat percentage are routinely available, whereas this is not the case for DMI.

\section{Prediction of Subclinical Ketosis Risk Across Consecutive Weeks}

In the second part of the study we investigated the forecast of BHBA status. Table 4 shows the effect of different prediction models (Mod1-7, lower part of Table 2 ) on the performance of ANN. The average Pearson correlation coefficient between observed and predicted BHBA concentration of 500 independent cross-validation runs is shown in Table 4. Predictions were achieved with combinations of information originating from 1 wk, aiming to predict the BHBA concentrations of the following week for individual cows. Because of data structure, the number of animals included in the different data sets was slightly lower than in the previous analyses. Therefore, variances of calculated correlations in the CV runs were higher than those obtained in runs within weeks (Tables 3 and 4). Increasing the number of independent CV runs $(>500)$ did not decrease variation of correlations between observed and predicted phenotype. To improve this aspect, a larger number of animals would be needed in single models. Additionally, based on the poor performance in the previous predictions, the GPC-to-PC ratio was dropped from the analyses (Table 2).

Results indicate that the prediction of BHBA status across consecutive weeks is generally applicable from wk 3 to 4 and wk 4 to 5 . Averaged over the 7 implemented predictive models, a Pearson correlation coefficient of 0.279 and 0.198 , respectively, was obtained in the data sets between observed and predicted milk BHBA concentrations. In comparison, predictive performance was worse from wk 2 to 3 (correlation averaged over all models $\mathrm{r}=0.048$ ), and predictions completely failed from the first to the second week postpartum (correlation averaged over all models $r=-0.081$ ). In the latter data set, no correlations between predicted and true value could be achieved. Because of the rapid changes in metabolism at the beginning of lactation (Drackley, 1999), milk-related and metabolic measurements can vary strongly in the first weeks in milk. Our assumption that some factors are mapping the concentration 
Table 4. Results of predictions across consecutive weeks ${ }^{1}$

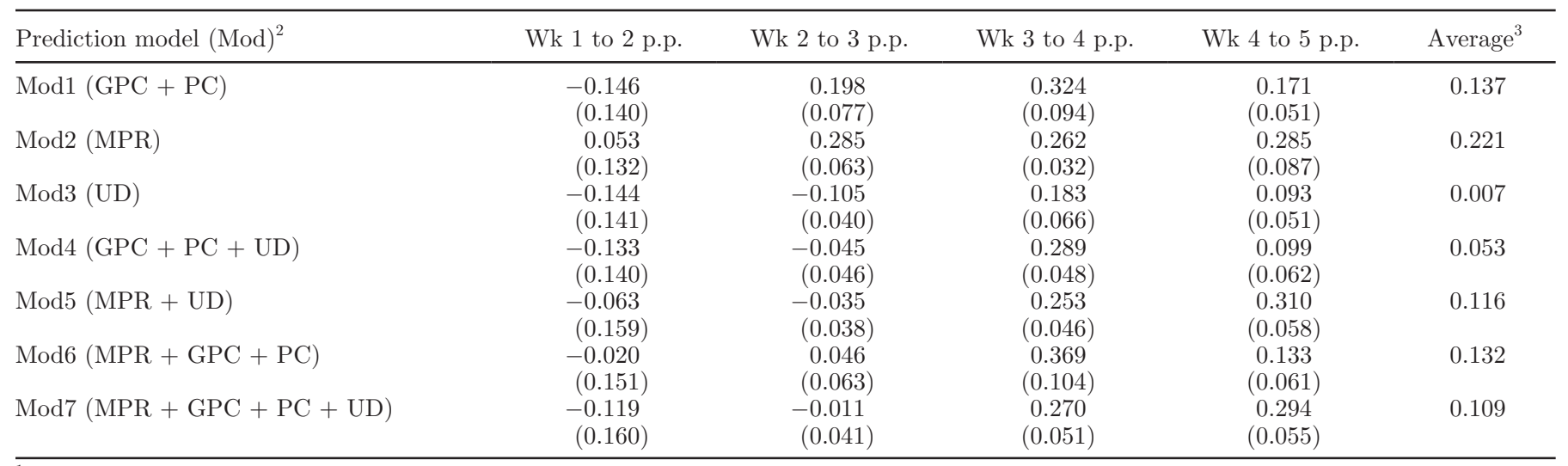

${ }^{1}$ Shown are the average Pearson correlation coefficients between observed and predicted BHBA concentrations in milk over all $500 \mathrm{CV}$ runs (the variance of estimates is given in parentheses). p.p. = postpartum.

${ }^{2} \mathrm{GPC}=$ glycerophosphocholine, $\mathrm{PC}=$ phosphocholine, $\mathrm{MPR}=$ milk performance records $($ milk yield, fat and protein percentage), UD = principal component scores of genotypes.

${ }^{3}$ Averaged over all weeks.

of BHBA across consecutive weeks might not be appropriate in the first 2 wk postpartum. Thus, a dynamic prediction model, e.g., time-series analyses, might be more reasonable than a static one. However, this also could be biased through low effective sample size as well as the limited number of animals with high milk BHBA concentrations.

Nevertheless, the results show that the forecast of SCK risk based on data from the previous week is possible with a reasonable quality from wk 2 to 5 postpartum. The best combination of predictors is, however, varying between weeks (Table 4). Results indicate no significant advantage of milk performance records over metabolic information as information sources. However, when milk performance records were provided as input to the ANN, more consistent results across different data sets were achieved. Unfortunately, the use of milk performance records in conjunction with milk concentrations of GPC and PC, both recorded 1 wk before, did not result in significantly better prediction performances of the network. Moreover, the performance of using genomic covariates as single models or in combination with other information was also low for wk 1 to 2 and 2 to 3 , respectively, whereas adding genetic information to prediction models for wk 3 to 4 and 4 to 5 , respectively, seemed to achieve more consistent prediction performances than single models.

In summary, the performance of incorporating metabolic, genetic, and milk performance data alone and in various combinations was compared in predicting BHBA concentrations by means of ANN in individual dairy cows within and across consecutive weeks postpartum. Predictive abilities differed across models. Overall, metabolic and performance-based models had a higher predictive ability than models based on genetic information. However, further studies using more comprehensive data sets have to be awaited to confirm these promising results. Furthermore, metabolites or metabolite profiles that possess a higher predictive ability than those used in the current study might exist.

\section{ACKNOWLEDGMENTS}

This research was supported by the German Federal Ministry of Education and Research (BMBF) in the context of the Fugato-plus MeGA-M framework (grant no. 0315131B) and the AgroCluster "Synbreed-Synergistic plant and animal breeding" (grant no. 0315528F). The genotyping of the cows was financially supported by the German Federal Ministry of Education and Research (project FUGATO-plus GENOTRACK, grant no. 0315134A), the KMSH (Kompetenzzentrum Milch-Schleswig-Holstein, Kiel, Germany), and the NOG Nord-Ost Genetic GmbH \& Co. KG (Verden, Germany). The authors thank P. Oefner for a thorough review of the manuscript and many helpful suggestions.

\section{REFERENCES}

Andersson, L. 1988. Subclinical ketosis in dairy cows. The Veterinary clinics of North America. Food Anim. Prac. 4:233-251.

Asl, A. N., S. Nazifi, A. R. Ghasrodashti, and A. Olyaee. 2011. Prevalence of subclinical ketosis in dairy cattle in the Southwestern Iran and detection of cutoff point for NEFA and glucose concentrations for diagnosis of subclinical ketosis. Prev. Vet. Med. 100:38-43.

Buitenhuis, A. J., U. K. Sundekilde, N. A. Poulsen, H. C. Bertram, L. B. Larsen, and P. Sørensen. 2013. Estimation of genetic parameters and detection of quantitative trait loci for metabolites in Danish Holstein milk. J. Dairy Sci. 96:3285-3295.

Buttchereit, N., E. Stamer, W. Junge, and G. Thaller. 2010. Relationship of energy balance and fat protein ratio of milk to disease 
liability in dairy cattle. Page 315 in Proc. World Congr. Genet. Appl. Livest. Prod. 2010, Leipzig, Germany.

Carlén, M., K. Meletis, C. Goritz, V. Darsalia, E. Evergren, K. Tanigaki, M. Amendola, F. Barnabe-Heider, M. S. Y. Yeung, L. Naldini, T. Honjo, Z. Kokaia, O. Shupliakov, R. M. Cassidy, O. Lindvall, and J. Frisen. 2009. Forebrain ependymal cells are Notch-dependent and generate neuroblasts and astrocytes after stroke. Nat. Neurosci. 12:259-267.

Collard, B. L., P. J. Boettcher, J. C. M. Dekkers, D. Petitclerc, and L. R. Schaeffer. 2000. Relationships between energy balance and health traits of dairy cattle in early lactation. J. Dairy Sci. 83:2683-2690.

Dohoo, I. R., and S. W. Martin. 1984. Subclinical ketosis: Prevalence and associations with production and disease. Can. J. Comp. Med. 48:1-5.

Drackley, J. K. 1999. Biology of dairy cows during the transition period: The final frontier? J. Dairy Sci. 82:2259-2273.

Duffield, T. F., D. F. Kelton, K. E. Leslie, K. D. Lissemore, and J. H. Lumsden. 1997. Use of test day milk fat and milk protein to detect subclinical ketosis in dairy cattle in Ontario. Can. Vet. J. 38:713-718.

Duffield, T. F., K. D. Lissemore, B. W. McBride, and K. E. Leslie. 2009. Impact of hyperketonemia in early lactation dairy cows on health and production. J. Dairy Sci. 92:571-580.

Enjalbert, F., M. C. Nicot, C. Bayourthe, and R. Moncoulon. 2001. Ketone bodies in milk and blood of dairy cows: Relationship between concentrations and utilization for detection of subclinical ketosis. J. Dairy Sci. 84:583-589.

Gaddis, K. L. P., J. B. Cole, J. S. Clay, and C. Maltecca. 2014. Genomic selection for producer-recorded health event data in US dairy cattle. J. Dairy Sci. 97:3190-3199.

Geishauser, T., K. Leslie, J. Tenhag, and A. Bashiri. 2000. Evaluation of eight cow-side ketone tests in milk for detection of subclinical ketosis in dairy cows. J. Dairy Sci. 83:296-299.

Gianola, D., H. Okut, K. A. Weigel, and G. J. Rosa. 2011. Predicting complex quantitative traits with Bayesian neural networks: A case study with Jersey cows and wheat. BMC Genet. 12:87.

Hamann, J., and V. Krömker. 1997. Potential of specific milk composition variables for cow health management. Livest. Prod. Sci. 48:201-208.

Heringstad, B., Y. M. Chang, D. Gianola, and G. Klemetsdal. 2005. Genetic analysis of clinical mastitis, milk fever, ketosis, and retained placenta in three lactations of Norwegian Red cows. J. Dairy Sci. 88:3273-3281.

Hornik, K., M. Stinchcombe, and H. White. 1989. Multilayer feedforward networks are universal approximators. Neural Netw. $2: 359-366$.

Howie, B., J. Marchini, and M. Stephens. 2011. Genotype imputation with thousands of genomes. G3 1:457-470.

Klein, M. S., M. F. Almstetter, N. Nürnberger, G. Sigl, W. Gronwald, S. Wiedemann, K. Dettmer, and P. J. Oefner. 2013. Correlations between milk and plasma levels of amino and carboxylic acids in dairy cows. J. Proteome Res. 12:5223-5232.

Klein, M. S., N. Buttchereit, S. P. Miemczyk, A.-K. Immervoll, C. Louis, S. Wiedemann, W. Junge, G. Thaller, P. J. Oefner, and W. Gronwald. 2012. NMR metabolomic analysis of dairy cows reveals milk glycerophosphocholine to phosphocholine ratio as prognostic biomarker for risk of ketosis. J. Proteome Res. 11:1373-1381.

Kohavi, R. 1995. A study of cross-validation and bootstrap for accuracy estimation and model selection. Pages 1137-1145 in the Proc.
Int. Joint Conf. Art. Intel. (IJCAI). Morgan Kaufmann Publ. Inc., San Francisco, CA.

Kriesel, D. 2007. A brief introduction to neural networks. Accessed Mar. 12, 2014. http://www.dkriesel.com.

LeBlanc, S. 2010. Monitoring metabolic health of dairy cattle in the transition period. J. Reprod. Dev. 56:S29-S35.

Li, Y., C. J. Willer, J. Ding, P. Scheet, and G. R. Abecasis. 2010. $\mathrm{MaCH}$ : Using sequence and genotype data to estimate haplotypes and unobserved genotypes. Genet. Epidemiol. 34:816-834.

Mandel, J. 1982. Use of the singular value decomposition in regression analysis. Am. Stat. 36:15-24.

Oikonomou, G., G. E. Valergakis, G. Arsenos, N. Roubies, and G. Banos. 2008. Genetic profile of body energy and blood metabolic traits across lactation in primiparous Holstein cows. J. Dairy Sci. 91:2814-2822.

Pérez-Rodríguez, P., D. Gianola, K. A. Weigel, G. J. M. Rosa, and J. Crossa. 2013. Technical note: An R package for fitting Bayesian regularized neural networks with applications in animal breeding. J. Anim. Sci. 91:3522-3531.

R Development Core Team. 2010. R: A Language and Environment for Statistical Computing. R version 2.14.1. R Found. Stat. Comp., Vienna, Austria. http://www.R-project.org.

Seifi, H. A., S. J. LeBlanc, K. E. Leslie, and T. F. Duffield. 2011. Metabolic predictors of post-partum disease and culling risk in dairy cattle. Vet. J. 188:216-220.

Suthar, V. S., J. Canelas-Raposo, A. Deniz, and W. Heuwieser. 2013. Prevalence of subclinical ketosis and relationships with postpartum diseases in European dairy cows. J. Dairy Sci. 96:2925-2938.

Tetens, J., T. Seidenspinner, N. Buttchereit, and G. Thaller. 2013. Whole-genome association study for energy balance and fat/protein ratio in German Holstein bull dams. Anim. Genet. 44:1-8.

Tusell, L., P. Pérez-Rodríguez, S. Forni, X. L. Wu, and D. Gianola. 2013. Genome-enabled methods for predicting litter size in pigs: A comparison. Animal 7:1739-1749.

van der Drift, S. G. A., R. Jorritsma, J. T. Schoneville, H. M. Knijn, and J. A. Stegeman. 2012a. Routine detection of hyperketonemia in dairy cows using Fourier transform infrared spectroscopy analysis of $\beta$-hydroxybutyrate and acetone in milk in combination with test-day information. J. Dairy Sci. 95:4886-4898.

van der Drift, S. G. A., K. J. E. van Hulzen, T. G. Teweldemedhn, R. Jorritsma, M. Nielen, and H. C. M. van Heuven. 2012b. Genetic and nongenetic variation in plasma and milk $\beta$-hydroxybutyrate and milk acetone concentrations of early lactating dairy cows. J. Dairy Sci. 95:6781-6787.

van Knegsel, A. T. M., S. G. A. van der Drift, M. Horneman, A. P. W. de Roos, B. Kemp, and E. A. M. Graat. 2010. Short communication: Ketone body concentration in milk determined by Fourier transform infrared spectroscopy: Value for the detection of hyperketonemia in dairy cows. J. Dairy Sci. 93:3065-3069.

Veerkamp, R. F., and E. P. C. Koenen. 1999. Genetics of food intake, live weight, condition score and energy balance. Pages $63-73$ in Occasional Publication of the British Society of Animal Science. No. 24. British Soc. Anim. Sci., Edinburgh, Scotland.

von Leesen, R., J. Tetens, E. Stamer, W. Junge, G. Thaller, and N Krattenmacher. 2014. Effect of genetic merit for energy balance on luteal activity and subsequent reproductive performance in primiparous Holstein-Friesian cows. J. Dairy Sci. 97:1128-1138. 